\title{
Public health principles into action in combating COVID-19 at workplaces
}

\section{Inoka Suraweera*, Lakshman Gamlath, Tilak Siriwardena, Niroshini Adikaram, Kumudu Weerakoon, Deepika Herath}

Directorate of Environmental, Occupational Health and Food Safety, Ministry of Health, Sri Lanka

„Correspondence: isuraweera@yahoo.com

(iDhttps://orcid.org/0000-0002-2764-0417

DOI: https://doi.org/10.4038/jccpsl.v26i5.8331

Received on 10 May 2020

Accepted on 5 June 2020

\begin{abstract}
Summary
The recent COVID-19 pandemic has caused a profound impact on all aspects of life, including the economy of the world at present. As economies of countries are largely interdependent requiring movement of cargo and human personnel involved in international trade, the major upheaval in the economies of USA, China and Europe caused by COVID-19 imposed trade and travel restrictions will have a negative impact across all countries of the world.
\end{abstract}

In Sri Lanka, the apparel, manufacturing, agriculture and tourism industries and the retail and consumer sectors are identified to be prominently affected, with small- and medium-scale enterprises being the worst hit by the restrictions imposed in the country to curtail the spread of COVD-19 (1). As the economy of the country has been negatively impacted, the Government of Sri Lanka has embarked on strengthening the economy and the Ministry of Healthcare and Indigenous Medical Services has been requested to facilitate this process, in ensuring the health and safety of the workers. The Directorate of Environmental and Occupational Health $(\mathrm{E} \& \mathrm{OH})$ being the national focal point for occupational health at the Ministry of Health, was entrusted with this important task. The Directorate has already carried out important activities in this regard in line with public health principles to ensure the health and safety of the workers as the workplaces steadily open up for operations. This article highlights the process followed in this task.

\section{Public health response and its impact}

At the hint of the onset of COVID-19 outbreak in Sri Lanka, the Directorate of E \& OH initiated the development of 'Guidelines on COVID-19 Preparedness for Workplaces'. This was finalized with inputs from senior medical administrators, senior microbiologists from the National Hospital of Sri Lanka, national professional officers from the World Health Organization (WHO) and consultant community physicians. These guidelines were widely disseminated to be utilized by workplaces with the objective of preventing and controlling the spread of COVID-19 infection among employees 
(Figure 1). In addition to actions, such as physical distancing, hand hygiene, respiratory etiquette, etc. that can be taken to prevent COVID-19, the guidelines also included common features of the disease, the current case definition and modes of transmission as COVID-19 is caused by a novel coronavirus. It was written in simple language with explanations for all and the modifications recommended. It is a comprehensive guide to modify workplaces to be equipped and employees to be empowered appropriately in view of being 'prepared' for COVID-19 infection

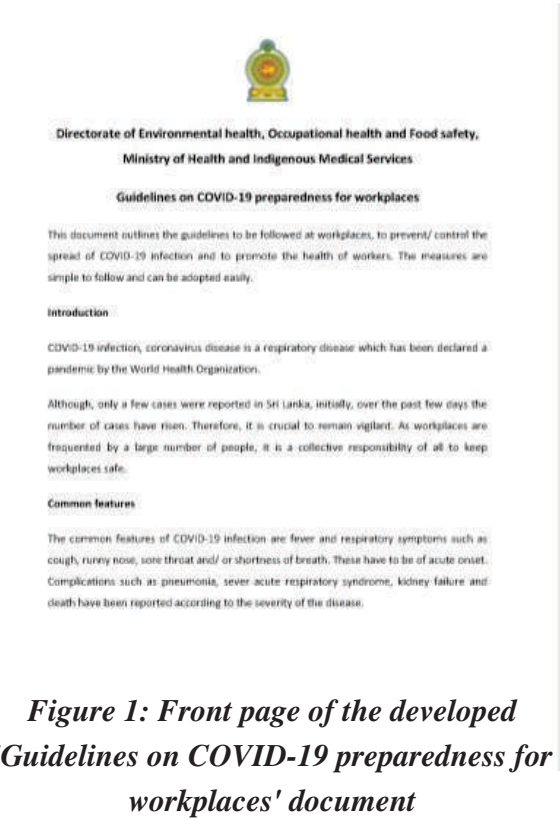

With the commencement of work, in the background of a pandemic, the workplaces need to adopt feasible and specific mechanisms in work settings to prevent any possible spread of COVID-19. Therefore, the necessity of publishing specific guidelines for different work settings was highlighted, 'Operational Guidelines for Preparedness and Response for COVID-19 Outbreak for Work Settings' was published following several consultative meetings with experts from various work settings, WHO and the Ministry of Health (2) (Figure 2). These operational guidelines included general and specific 'easy-to-adopt' recommendations which covered a large spectrum of workplaces. Further, it provided information on all the offices of medical officer of health $(\mathrm{MOH})$, regional director of health services (RDHS) and provincial director of health services (PDHS) in the country for end users in different sectors to access for advice and inputs.

Guidance on developing a workplace COVID-19 preparedness plan, guidance for cleaning and disinfection, special responsibilities of the management are some of the topics covered in the general guidelines, while the specific guidelines provide instructions to be followed in a range of work settings, from the manufacturing industry to universities.

These operational guidelines have been printed in all three languages and have been distributed throughout
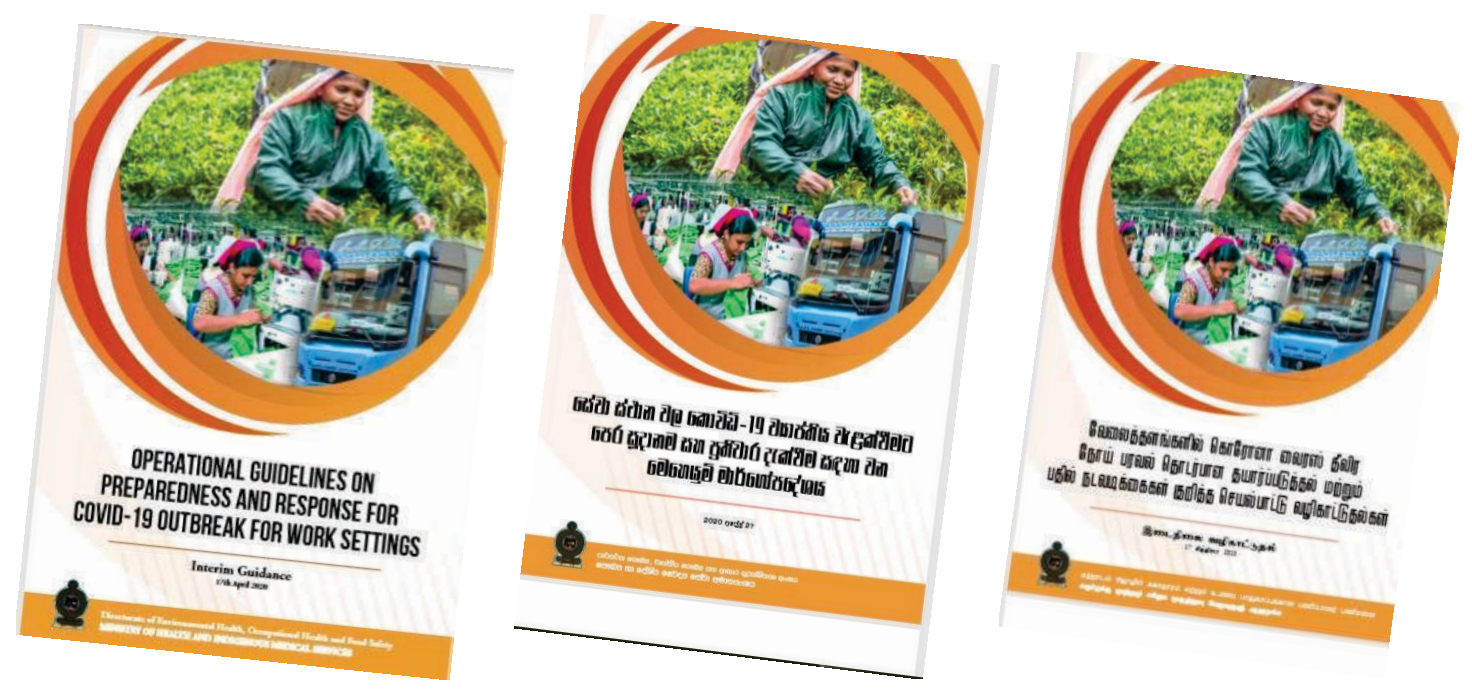

Figure 2: Cover of the book 'Operational guidelines on preparedness and response for COVID-19 outbreak for work settings' (English, Sinhala and Tamil versions) 
the country. It is hoped that these guidelines will be strictly adhered to by the relevant authorities and contribute to eliminating COVID-19 from the country, as responsible citizens.

A further set of specific guidelines as addendum to the operational guidelines was developed as it deemed necessary. Specific guidelines for the construction sector, banking sector, salons etc. have been developed with wide stakeholder consultations. The enthusiasm and the contribution from the sector representatives in the development process of these specific guidelines are remarkable (2-3). It is expected to use these specific guidelines to guide the public health staff as well as the employers in further strengthening COVID-19 prevention activities at work settings.

Additionally, circular guidelines have been issued with regard to the facilitation of operations in tea factories and export processing and manufacturing industries to the public health staff, to ensure the health and safety of these workers, as these factories continued to function even during curfew (2). Experts from the $\mathrm{E} \& \mathrm{OH}$ Unit are currently in the process of providing technical guidance for the development of health guidelines for holding general elections in Sri Lanka, as many workers are involved in this process the Directorate has to ensure their health and safety. Sri Lanka, though a small island, has a wide range of work settings with unique concerns. This has necessitated the development of separate guidelines for different work settings, within a short period of time, to ensure the smooth functioning of workplaces, during this COVID-19 crisis. These guidelines are subject to further modification with the availability of new knowledge on the virus and on the local and global situation of the pandemic.

\section{Education and empowerment}

A series of discussions and meetings were conducted at all Board of Investment (BOI) Zones throughout the country to discuss the facilitation process of operations in industries and the scaling-up of activities. These were attended by $\mathrm{E} \& \mathrm{OH}$ national level officials, provincial, district and divisional level health officials, the BOI executive director, zonal directors, senior police officers, labour officers, and representatives from industries. With an initial introduction to the topic on COVID-19 preparedness, the health officials created awareness about the health threats and recommendations to be adhered to safeguard all workers. The discussion gave opportunity to the audience to clarify concerns and they were empowered to continue with the prevention activities at their workplaces. These discussions were found to be very fruitful.

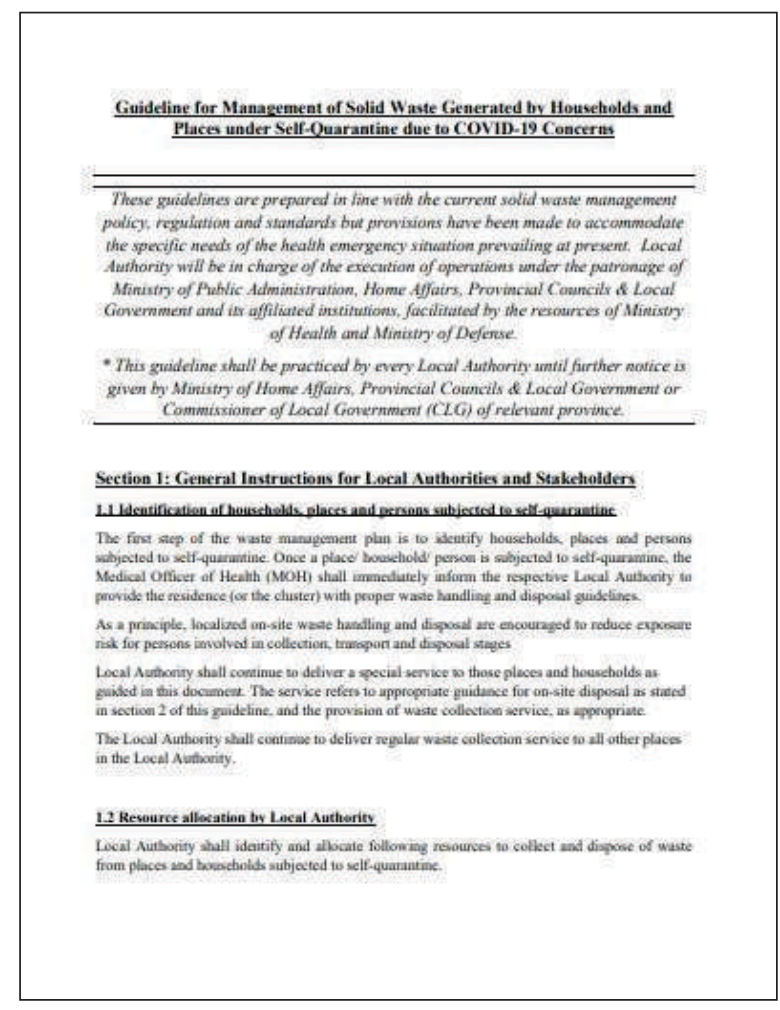

Figure 5: Front page of the developed

'Interim Guideline for Management of Solid Waste Generated by

Households and Places under Self-Quarantine due to COVID-19 Concerns' document

\section{Conclusions}

Environmental and occupational health has been a competing priority in Sri Lanka. However, it is no more. The importance of having a healthy workforce and a clean environment is well realized. It is hoped that the tireless actions, governed by public health principles, taken by the Directorate of $\mathrm{E} \& \mathrm{OH}$ during this crisis period would pave the way for strengthening the economy of our country and help 
reduce environmental pollution at least to a certain extent. The Directorate is optimistic to march forward with all stakeholders during these difficult times, and to be a pillar in regaining the economic as well as environmental stability of Sri Lanka.

\section{Author Declaration}

Acknowledgements: We would like to acknowledge with gratitude all the resource persons contributing to the development of circulars and guidelines and to the funding agents for the support provided in printing the guidelines.

Author contributions: IS contributed to planning and writing the manuscript, participated, coordinated and conducted all the activities described in the narrative summary. LG contributed by initiating, coordinating and participating in the activities described in the narrative summary. TS contributed by coordinating and participating in the activities described in the narrative summary. DH contributed to designing and writing the manuscript. Contributed to activities described in the narrative summary. NA contributed by giving inputs and editing the manuscript and contributed to the activities described in the narrative summary. KW contributed by giving inputs and editing the manuscript. Contributed to the activities described in the narrative summary.
References

1. Jansz J. The impact of COVID-19 on the Sri Lankan Economy. Pulse, 20 April 2020. Available from: http://www.pulse.lk/ everythingelse/the-impact-ofcovid-19-on-the-sri-lankan-economy/.

2. Ministry of Health \& Indigenous Medical Services. Operational Guidelines on Preparedness and Response for COVID-19 Outbreak for Work Settings. NEWS HEADLINE. Available from: http://www. health. gov.lk/moh_final/english/article_read_more. php?id=861. Accessed 8 May 2020

3. Occupational Health Unit. COVID Guidelines. Ministry of Health. Available from: http://eohfs .health.gov.lk/occupational/index.php?option=com_c ontent $\&$ view=article $\&$ id=61\&Itemid=208\&lang=en. Accessed 8 May 2020.

4. Ministry of Provincial Councils, Local Government \& Sports. Interim Guideline for Management of Solid Waste Generated by Households and Places under Self-Quarantine due to COVID-19 Concerns. Available from: http://www.lgpc.gov.lk/web/index. php?lang=en. Accessed 8 May 2020. 